\title{
The burden of genetically determined eye disease
}

\author{
JANE S GREEN, JOHN C BEAR, AND GORDON J JOHNSON \\ From the Division of Community Medicine and Discipline of Surgery, Faculty of Medicine, Memorial \\ University of Newfoundland, St John's, Newfoundland, Canada
}

SUMmaRY We determined the underlying aetiology of blindness for the registered blind population of the Province of Newfoundland and Labrador. In both 1981 and 1984 single-gene disorders accounted for $30 \%$ of total blindness and congenital defects for another $10-11 \%$. Genetically determined conditions, diabetes, and senile macular degeneration (SMD) were the three leading causes of registration in each year, 1980-4. We calculated mean ages of registration and mean ages of death over the last four years for five major aetiological groups. Patients with genetic conditions were registered at a much younger age and had a correspondingly longer duration of blindness (21 years as compared with 5 years for either diabetes or SMD). Total 'person-years of blindness' was then calculated from the product of this duration of blindness and the total numbers registered in each group. This index shows that the overall individual and population impact of monogenic blindness is overwhelmingly greater than that of other causes (6849 person-years compared with 270 for diabetes and 430 for SMD). In view of this frequency and duration of monogenic blindness, and also of the substantial hereditary liability to relatively common causes of blindness such as glaucoma, diabetic retinopathy, and high myopia, we suggest that more attention needs to be paid to elucidating the genetic contribution to blindness.

There is a growing awareness of the importance of genetic disease as a cause of blindness. For example, a recent paper from Saudi Arabia' reported a changing pattern of aetiology, so that fully $84 \%$ of childhood blindness in that country is now caused by hereditary conditions.

Three years ago we reported on the causes of registered blindness in Newfoundland at the end of $1981 .^{2}$ Our aim was to determine as accurately as possible the underlying aetiology of blindness in each case, based on a review of the files of all persons registered with the Canadian National Institute of the Blind (CNIB) and examination of as many as possible of those cases for which the reported cause of registration was ambiguous. Single-gene disorders accounted for at least $30 \%$ of all registered blindness.

We have now brought this review of records up to date, tabulating the new registrations for the past three years. We present here analyses comparing 1981 and 1984. We are also interested in the relative burden to the population of different causes of blindness, and therefore determined 'person-years of Correspondence to Jane S Green, Community Medicine Health Sciences Centre, St John's, Newfoundland, Canada A1B 3V6. blindness' for the different categories as an index of the personal and population impact of each.

\section{Patients and methods}

The Canadian Province of Newfoundland and Labrador has a total population of approximately 580000 , the majority of whom live in relatively isolated, scattered coastal communities. The legal responsibility for the registration of blindness rests with the CNIB. Registration is not obligatory at present. The criteria for registration, only one of which need be met, are (a) corrected visual acuity of $6 / 60$ or worse in the better eye, and $(b)$ a total visual field of less than $10^{\circ}$ from fixation using a white target $10 \mathrm{~mm}$ in diameter at a distance of $1 \mathrm{~m}$.

The files of all persons registered on 31 December 1981 had previously been analysed in detail to determine the aetiological category. ${ }^{2}$ Persons newly registered in each of the years 1980-4 have now been analysed in the same way. If there was some ambiguity in the diagnosis or aetiological code, an attempt was made to examine the patient. We have examined a total of 350 of the 1041 registered 
patients. In the case of retinal dystrophies and related conditions this examination included colour vision testing, dark adaptation, and electroretinography. Although glaucoma, diabetic retinopathy, and high myopia may have a strong genetic component, these entities were tabulated separately, not under established or presumed genetic disease.

The ages of death of all registrants dying in the years 1981-4 were obtained, as were their ages at registration. From these numbers were calculated the mean ages of registration for each major aetiological category, the duration of blindness to the nearest whole year of each deceased registrant, and the mean duration of blindness for each major aetiological category. For comparison the mean ages of registration for all registrants and for those first registered in the last five years were calculated. The determination of mean years of blindness is possible only for the period 1981-4, during which CNIB files have been monitored, as no continuing record is kept of age at registration and age at death of those deceased in earlier decades.

For each aetiological category we multiplied mean duration of blindness for deceased registrants (1981-4) by the overall number of patients in the category as at 31 December 1984 to arrive at 'personyears of blindness', an indicator of the relative burden to the population of each major cause of blindness.

\section{Results}

As at 31 December 1984, 1041 individuals were registered blind in the Province. Two hundred and fifty-three $(24 \%)$ of these were blind because of single-gene disorders such as the retinal dystrophies, albinism, aniridia, or autosomal dominant cataracts, established by examination (Table 1). Another $5 \%$ were presumed to have genetic disorders on the basis of family history of such conditions as nystagmus or optic atrophy, but were not seen by us. The congenital group included some unidentified simplex cases of the genetic forms of cataract, coloboma, or microphthalmos. Senile macular degeneration (SMD), diabetic retinopathy, and glaucoma (each of which may be regarded as being multifactorial in aetiology), which are frequently noted elsewhere as leading causes of blindness, occurred much less often in this Newfoundland series than did monogenic blindness.

Between 1981 and 1984 there was only a small increase in the total number registered, from 1013 to 1041 (Table 1). The genetic and congenital proportions were unchanged, comprising over $40 \%$ of registrations. The proportions of myopia and glaucoma were also unchanged. There was an increase in the number of cases of senile macular degeneration. Blindness from infectious disease and trauma had decreased slightly in frequency. There were more deaths of elderly affected patients in these groups than new registrations. Fewer diabetics were registered now than previously; this reflects only imperfectly the high mortality in this group (see below).

Table 2 shows the registrations in each of the past five years. Except in 1983, when few diabetics were registered, senile macular degeneration, genetic conditions, and diabetic retinopathy were consistently the top three causes of registration.

The mean age at registration for the new registrants of the past five years was similar to that of the total registrations in each of the five major aetiological groups (Table 3). The mean ages of registration of

Table 1 Causes of blindness in all persons registered with the Canadian National Institute for the Blind in Newfoundland and Labrador on 31 December 1981 and 31 December 1984

\begin{tabular}{lrrrr}
\hline & \multicolumn{3}{c}{1981} & \multicolumn{3}{c}{1984} \\
\cline { 2 - 5 } & Number $\%$ & Number $\%$ \\
\hline Genetic established & 243 & $24 \cdot 0$ & 253 & $24 \cdot 3$ \\
Genetic presumed & 56 & $5 \cdot 5$ & 56 & $5 \cdot 4$ \\
Congenital: cataract and & 110 & $10 \cdot 9$ & 116 & $11 \cdot 1$ \\
$\quad$ multiple anomalies & 100 & $9 \cdot 9$ & 100 & $9 \cdot 6$ \\
High myopia & 60 & $5 \cdot 9$ & 86 & $8 \cdot 3$ \\
Senile macular degeneration & 88 & $8 \cdot 7$ & 77 & $7 \cdot 4$ \\
Infectious disease & 67 & $6 \cdot 6$ & 62 & $6 \cdot 0$ \\
Trauma and poisoning & 59 & $5 \cdot 8$ & 54 & $5 \cdot 2$ \\
Diabetic retinopathy & 48 & $4 \cdot 7$ & 49 & $4 \cdot 7$ \\
Glaucoma & 41 & $4 \cdot 0$ & 42 & $4 \cdot 0$ \\
Vascular and other systemic & & & & \\
$\quad$ disease & 34 & $3 \cdot 4$ & 29 & $2 \cdot 8$ \\
Senile cataract & 22 & $2 \cdot 2$ & 21 & $2 \cdot 0$ \\
Tumour & 61 & $6 \cdot 0$ & 68 & $6 \cdot 5$ \\
Other & 24 & $2 \cdot 4$ & 28 & $2 \cdot 7$ \\
Undetermined & 1013 & $100 \cdot 0$ & 1041 & $100 \cdot 0$ \\
Total & & & & \\
\hline
\end{tabular}

Table 2 Causes of blindness registration in each of the years 1980-4

19801981198219831984 Total

\begin{tabular}{lrrrrrr}
\hline Senile macular degeneration (SMD) & 11 & 18 & 12 & 18 & 11 & 70 \\
Genetic (established and presumed) & 15 & 13 & 10 & 17 & 9 & 64 \\
Diabetic retinopathy & 15 & 11 & 10 & 3 & 13 & 52 \\
Congenital & 7 & 8 & 3 & 4 & 4 & 26 \\
Glaucoma & 3 & 6 & 3 & 8 & 3 & 23 \\
Trauma and poisoning & 5 & 7 & 5 & 1 & 2 & 20 \\
High myopia & 6 & 6 & 4 & 2 & 1 & 19 \\
Vascular and other systemic disease & 0 & 1 & 4 & 5 & 6 & 16 \\
Senile cataract & 5 & 3 & 2 & 3 & 2 & 15 \\
Infectious disease & 2 & 3 & 1 & 2 & 1 & 9 \\
Tumour & 1 & 0 & 1 & 0 & 1 & 3 \\
Other and undetermined & 7 & 4 & 5 & 6 & 3 & 25 \\
Total & 77 & 80 & 60 & 69 & 56 & 342 \\
\hline
\end{tabular}


Table 3 Mean ages at registration in five selected aetiological categories (years $\pm S D$ )

\begin{tabular}{llll}
\hline & Total registration & $\begin{array}{l}\text { New registrations } \\
1980-4 \\
(n=342)\end{array}$ & $\begin{array}{l}\text { Persons dying } \\
1981-4 \\
(n=175)\end{array}$ \\
\hline Diabetes & $56( \pm 16)$ & $53( \pm 18)$ & $61( \pm 14)$ \\
SMD & $74( \pm 9)$ & $77( \pm 7)$ & $77( \pm 7)$ \\
Glaucoma & $62( \pm 17)$ & $73( \pm 17)$ & $71( \pm 12)$ \\
Myopia & $46( \pm 16)$ & $57( \pm 17)$ & $58( \pm 11)$ \\
Genetic & $25( \pm 16)$ & $25( \pm 20)$ & $46( \pm 19)$ \\
\hline
\end{tabular}

Table 4 Mean years of blindness in five aetiological categories of those registered blind persons who died during 1981-4

\begin{tabular}{lclll}
\hline & $\begin{array}{l}\text { Number of } \\
\text { deaths }\end{array}$ & $\begin{array}{l}\text { Meanage at } \\
\text { registration }\end{array}$ & $\begin{array}{l}\text { Meanage } \\
\text { at death }\end{array}$ & $\begin{array}{l}\text { Meanyears } \\
\text { ofblindness }\end{array}$ \\
\hline Diabetes & 39 & 61 & 66 & 5 \\
SMD & 23 & 77 & 82 & 5 \\
Glaucoma & 15 & 71 & 81 & 10 \\
Myopia & 7 & 58 & 75 & 17 \\
Genetic & 22 & 46 & 67 & 21 \\
& \multicolumn{5}{c}{ Total deaths 175} \\
\hline
\end{tabular}

Table 5 Expected total 'person-years of blindness' in five aetiological categories, based on blind population registered on 31 December 1984

\begin{tabular}{lccc}
\hline & $\begin{array}{l}\text { Number } \\
\text { registered }\end{array}$ & $\begin{array}{l}\text { Meanyears } \\
\text { of blindness }\end{array}$ & $\begin{array}{l}\text { Person-years } \\
\text { of blindness }\end{array}$ \\
\hline Diabetes & 54 & 5 & 270 \\
SMD & 86 & 5 & 430 \\
Glaucoma & 49 & 10 & 490 \\
Myopia & 100 & 17 & 1700 \\
Genetic & 309 & 21 & 6489 \\
\hline
\end{tabular}

those who died within the past four years were also comparable, except for the genetic category; in this case the mean age of registration was 46 years, compared with 25 years for recent registrations and total registrations.

One hundred and seventy-five registrants died during 1981-4 (Table 4). The deaths in the diabetic retinopathy group were markedly out of proportion to their representation in the total sample; of 79 diabetics registered at some time during 1981-4, 39 died within that interval. During the same time 23 of 102 with senile macular degeneration died and only 22 of 326 with genetic conditions.

Persons with diabetic retinopathy and senile macular degeneration experienced on average five years of blindness, persons blind owing to high myopia 17 years, and persons blind due to monogenic conditions 21 years (Table 4). In the total registered blind population the 'person-years of blindness' attributable to diabetes were 270, to SMD 430, and to genetic diseases 6489 (Table 5).

\section{Discussion}

In analysing the records of all the registered blind persons in the Province our first goal was to determine as accurately as possible the underlying aetiology of the blindness. As has previously been discussed, in $15 \%$ of cases either the recorded cause of blindness or the aetiology code was found to be incorrect. ${ }^{2}$ However, by undertaking this study in a geographic area with a relatively small and stable population we could establish family histories relatively easily and frequently examine patients with ambiguous records to establish diagnoses.

The high frequency of genetic blindness in Newfoundland is not a reflection of ascertainment due to our research interests. Rather than a recent increase in the proportion of monogenic blindness we are demonstrating a continued high prevalence. Singlegene disorders accounted for $30 \%$ of total blindness in our initial study in 1981, reflecting the high prevalence of this type of blindness over previous years.

The increase in senile macular degeneration in the 1981-4 interval may indicate improved ascertainment or a real increase as the life expectancy of the general population increases. In this interval there have been few new registrations in the categories of infection and trauma, presumably because of imprcved treatment, and the overall representation of these categories has decreased. New cases of blindness in younger people due to infection and trauma are unlikely to have escaped detection and registration in this well defined population. The cases which are more likely to escape registration at the appropriate level of vision are those due to slowly progressive diseases in older people-senile macular degeneration, diabetic maculopathy, and glaucoma.

It may be asked whether the high proportion of genetically determined blindness in Newfoundland is explained by the Province's population genetic structure. The population derives primarily by natural increase from settlers who arrived before 1835 , drawn from highly circumscribed areas of south-western England and southern Ireland. Hundreds of small communities have grown up around Newfoundland's many natural harbours. At present about $50 \%$ of the population of the Province reside in communities of fewer than 2500 inhabitants, and $41 \%$ reside in communities of fewer than 1000 . These small subpopulations remain genetically isolated (Bear JC, Nemec TF, Kennedy JC, et al., unpublished data). The low levels of migration into these communities and of genetic exchange between them contrast with observations from numerous studies of European isolates of comparable size where there has been increasing genetic exchange in 
this century. Thus frequencies of specific recessive disorders may be increased owing to inbreeding. Because closely consanguineous unions tend to be avoided, the matings are usually between distant relatives, and the frequency of a recessive disorder is reasonably ascribed to founder effect (the chance presence of an allele in relatively few original settlers of a genetically isolated population). Several instances of locally raised frequencies of autosomal dominant and $\mathrm{X}$-linked ocular disorders, such as von Hippel-Lindau disease and ocular albinism, have also been described, again reasonably attributed to founder effect. Conversely, just as some deleterious alleles are found in unusually high frequency, it is to be expected that some will be infrequent or absent, and indeed no examples of Best's macular dystrophy or of choroideraemia have been identified.

It must be emphasised that a high proportion of blindness due to hereditary disease is also indicated in studies elsewhere. In a county in Norway $29.6 \%$ of blind people (vision $6 / 60$ or less) had hereditary or probably hereditary diseases. ${ }^{3}$ Genetically determined conditions accounted for $77 \%$ of childhood blindness in Lebanon, ${ }^{4} 79 \%$ in Cyprus (of which half were autosomal recessive), ${ }^{5}$ and $84 \%$ in Saudi Arabia as already noted.' We have previously shown that the prevalence of genetic eye disease in Newfoundland was underestimated because of errors and ambiguities in coding at the time of registration of blindness. ${ }^{2}$ This underestimation could also apply to other studies where it was not possible to review all files in detail or examine as many of the patients when there was ambiguity in the coding.

Persons with monogenic blindness, as a group, are registered much younger than other blind persons, and consequently have a much longer duration of blindness. Although the mean years of blindness calculated for the group of 22 who died in 1981-4 was 21 years, higher than for other groups, this none the less greatly underestimates the usual duration of monogenic blindness. The mean age of registration for the most recent registrants in the genetic group is 25 years (Table 3 ), not 46 years as in the small group who died recently. The mean years of blindness of the genetic group as a whole may therefore be expected to be around 42 years rather than 21 years and attributable 'person-years of blindness' about 13000 . Not only are monogenic conditions the leading cause of blindness, but also in 'person-years of blindness', the overall individual and population impact of monogenic blindness is overwhelmingly greater than that of other forms of blindness.

The mean duration of blindness attributed to SMD and diabetes was five years. Senile macular degeneration causes blindness primarily in elderly people with a short life expectancy. Although the mean age of registration for diabetics is lower, sometimes in the interval 20-30 years, life expectancy of this group is unfortunately very poor. In fact, of the 15 diabetics registered in 1980, 10 were deceased by 1985 , compared with six of the 62 registered for other causes in 1980. Several young juvenile-onset diabetics died within one or two years of registration.

It is noteworthy that the genetic group appears to have a relatively low mean age of death (67 years), only one year higher than diabetics (66 years). If premature mortality among blind people with genetic disease is substantiated in studies of larger numbers of registrants, it will be important to try to determine what factors contribute to this. (Perhaps SMD and glaucoma registrants seem relatively long lived because these disorders are associated with advanced age.)

Regardless of the exact proportion of monogenic blindness in a particular country, the extra 'personyears of blindness' are relevant in all countries in which infectious and nutritional causes of blindness are adequately controlled. Moreover, the total genetic contribution to blindness extends well beyond the category of monogenic blinding disorders. Diabetes and glaucoma each show familial aggregation, and the genetic component in the liability to each is substantial. High myopia frequently seems strikingly familial.

While it remains of great importance to provide support through low-vision services, itinerant teachers for the visually impaired, and employment counselling, much more attention should be paid to elucidating the genetic component of blindness. This includes accurate diagnosis to provide specific recurrence risks for genetic counselling, clarification of the natural history and prognosis of individual disorders to provide specific advice for affected persons, and genetic linkage studies, to allow carrier detection and presymptomatic identification of affected individuals.

We thank Eugene Pike, Ruth Dyer, and Vera Tuck of the CNIB in St John's for their assistance and Dr Clarke Fraser for his constructive criticism.

The investigation was continued while the authors were recipients of a grant from the MRC of Canada.

\section{References}

1 Tabbara KF, Badr IA. Changing pattern of childhood blindness in Saudi Arabia. Br J Ophthalmol 1985; 69: 312-5.

2 Green JS, Johnson GJ. Hereditary diseases as causes of blindness in Newfoundland: preliminary report. Can J Ophthalmol 1983; 18: $281-4$.

3 Odland $M$. Hereditary diseases of the eye in a study of blind and partially sighted. Acta Ophthalmol (Kbh) 1981; 59: 275-85.

4 Baghdassarian SA, Tabbara KF. Childhood blindness in Lebanon. Am J Ophthalmol 1975; 79: 827-30.

5 Merin S, Lapithis AG, Horovitz D, Michaelson IC. Childhood blindness in Cyprus. Am J Ophthalmol 1972; 74: 538-42.

Accepted for publication 30 December 1985 